\title{
Differences of Street Connectivity Between Old and New Zone in Malaysian Small Town
}

\author{
Ismail Said ${ }^{\#}$ Wan Saiful Nizam Wan Mohamad ${ }^{\#}$ \\ \# Department of Landscape Architecture, Universiti Teknologi Malaysia, 81310, Malaysia \\ E-mail: b-ismail@utm.my;wsnizam2@live.utm.my
}

\begin{abstract}
From the period before Malaysia's independence until now, there are two significant characteristics of the town formed in small town. Pedestrian behavior in the streets is affected by the connectivity existed from the pattern of the street network of a town. Thus, the existing of characteristics of new and old zone require the pedestrian to travel differently in those environments. By considering a small town consists of the old and new zone and population between 30,000 to 100,000, a street network of Bandar Teluk Intan, Perak was selected. Three sets of data were produced from the land use map and Google Map image, then analyzed it using UCL Depthmap 10. Firstly, solid and void data was used in Visibility graph analysis to measure street connectivity from pedestrian visualization. Second data which convex space data used in Convex space graph analysis to measure street connectivity of spaces in street network that offer pedestrian interaction. Axial-line data is the third data was used in Axial-line graph analysis to measure street connectivity from pedestrian movement in the street network. Finding shows that in the old zone, junctions act as a connector to other streets when pedestrian visualize during travel, space in square and market chose as a meeting place, and the main road as a guide when pedestrian move. In new zone, the main road is a connecting feature for a pedestrian because it's easy to find, connect with most streets, and the possible space to meet people during travel.
\end{abstract}

Keywords - street network; street connectivity; visibility analysis; convex space analysis; axial-line analysis

\section{INTRODUCTION}

This study focused on connectivity form from a pedestrian that used space in the street network. According to [1] and [2], these known as street connectivity. Street connectivity is defined as the number of nodes linked to other nodes where a node can be a point represents a space or an intersection. A study in health and place employed street connectivity to measure physical activity which found that high connectivity in streets create an opportunity for people to do activities such as walking because of easy access to major roads where public transport is available [3]. A study in social science and medicine exposed the influence of street connectivity with walkability and found that street connectivity that affected by the physical structure of the street network, create perceptions of resource quality, safety, and cultural relevance leads to physical activity [4]. Thus, both findings show the relation of street connectivity with the town characteristic which exposed the different behavior of pedestrian when travels.

Small towns in Malaysia have experienced the urban formation which leads to the two significant town characteristics; old zone and new zone in town. The urban morphology study indicates the street network of Malaysian towns had an indelible impact toward Portuguese, Dutch, and British that introduced grid-like and geometric structures from Euclidean geometry concept in town planning and design [5]. After the towns ruled by a government of the Federation in 1957, the development then grew rapidly according to Malaysian town and country planning act [6]. These have influences pedestrian behavior when traveling because of the town characteristics. Therefore, the aim is to identify the differences of street connectivity between two significant town characteristics which old and new zones in Malaysian small town.

The street connectivity parameters used in this study are determined based on the space syntax approach [7]-[10]. For example, visibility is a parameter that connecting user to visualize in an underground metro station [11]. Convex space is used to measure the connectivity of interaction space which extracts topological information in buildings [12]. Axial-line is employed in determining the change of user movement after the implementation of historical and cultural prevention project in South Haliç Area in Istanbul [13]. The determined parameter for street connectivity measurement: visibility, convex space and axial-line. 


\section{A. Visibility for Pedestrian Visualization}

Visibility helps pedestrian to gain information from urban environments. In space syntax study, visibility is described as a node that can visualize other nodes in an environment [7]. References [14], [15], and [16] discussed visibility in air transportation management study as the number of sight lines from the total number of sight lines in an environment. In computing, environment and urban systems study focused visibility as the location that can observe various viewpoints which could determine navigators need such as their initial locations, destinations and finding landmarks [17]. Thus, the meaning of visibility is the connectivity of a node which is a location or point, with various nodes through pedestrian visualization or sight.

In this paper, visibility is a parameter used to determine street connectivity of selected the street network based on the space syntax approach. Based on the space syntax, street connectivity for visibility is defined as a number of the nodes viewed $\left(n_{i j}\right)$ connected with a node [7], [11], [18]. A node is represented by the center of a space with an area of $1.5 \mathrm{mx} 1.5 \mathrm{~m}$.

$$
C_{\text {visibility }}=\sum n_{i j}
$$

Based on Fig.1, connectivity for visibility $\left(C_{\text {visibility }}\right)$ in the graph refers to Equation 1 which analyzed using visibility graph analysis.

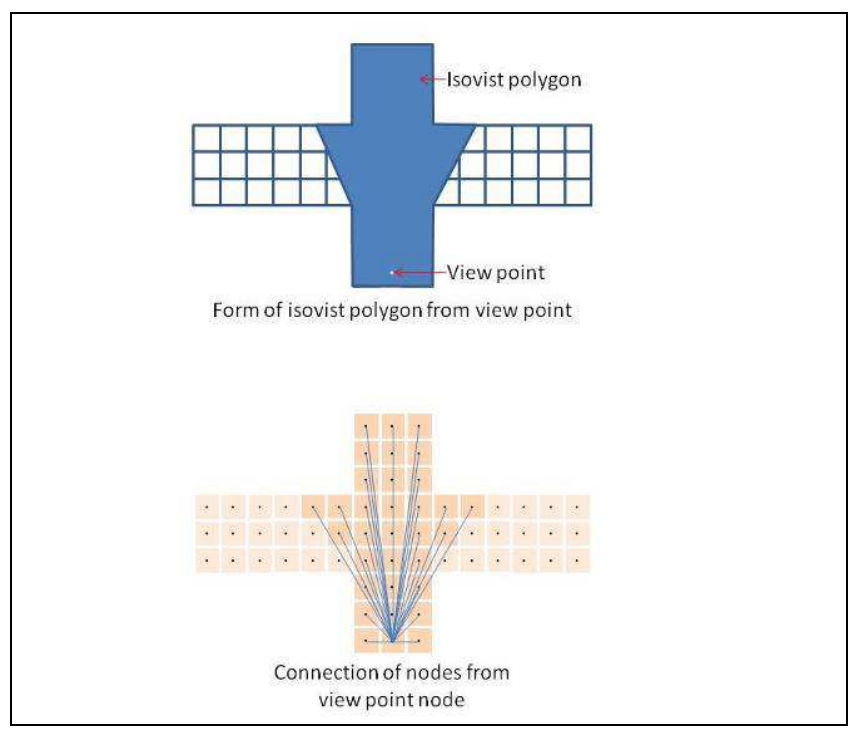

Fig. 1 Street connectivity for visibility

\section{B. Convex space as Space for Pedestrian Interaction}

Urban space is a place where pedestrian having a meeting for interaction. In space syntax study, pedestrian interaction is the space to interact which defined with a polygon known as convex space [8]. Convex space is defined as a boundary of space which has points that can be joined with all other without passing out the boundary [11]. A study by [8] on a layout of the school found that corridor is a space where interaction happens between teachers and students. Then, [19] used convex space to identify the topological information in the building based on human interaction. In the urban context, [13] analyzed convex space of historical components in Haliç, Istanbul and found that connection of the interaction space has strengthened the value of historical, cultural, social, physical and symbolic features to be appreciated. Thus, the degree of street connectivity for pedestrian interaction has given the meaning to the town.

This paper used convex space to determine street connectivity of street network for pedestrian interaction in town. Convex space has been introduced in space syntax approach as polygons that connect with each other in a compound such as a street network. Street connectivity in convex spaces is defined as a number links $\left(l_{i j}\right)$ that connected with other nodes of the spaces [8], [11], [12], [20], [21]. Based on Fig.2, a convex space has represented by a node at the center of the polygon.

$$
C_{\text {interaction }}=\sum l_{i j}
$$

Thus, the connectivity for pedestrian interaction $\left(C_{\text {interaction }}\right)$ in the graph is measured using convex space graph analysis based on Equation 2.

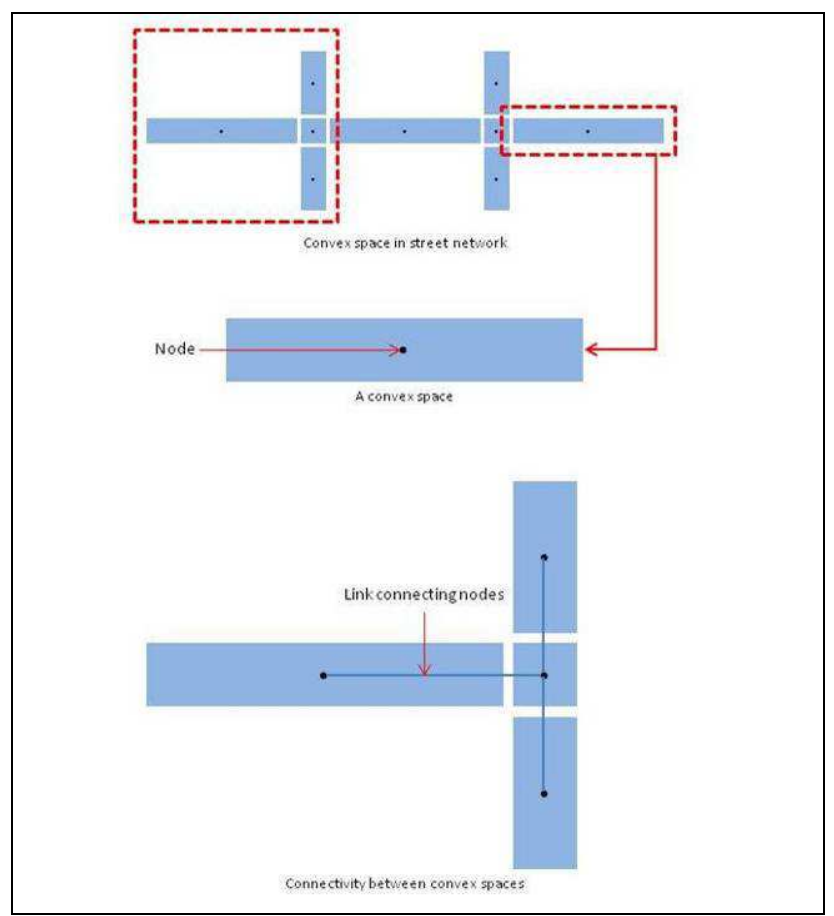

Fig. 2 Street connectivity for convex space

\section{Axial-line as Pedestrian Movement}

Street in town is a public place where people used to move to a destination for any purpose. It is a motivated activity involved with two points; origin point and destination point. In a socio logic space, free space such as a street allowed pedestrian move straight from a start toward the end of the street [22]. Thus, space syntax studies defines straight line formed from the pedestrian movement as axialline [7], [8], [11], [23], [24]. A study on tunnelling and underground space technology analyzed axial-line of the Bockstael metro station and the Anneessens premetro station to improve the design of urban underground space [11]. The finding of the study suggests that main gate highly influence 
movement in both metro stations, meaning that degree of connectivity for the space based on movement is dependent on the main gate. In the urban context, axial-line is used to measure 40 topological patterns that fit with pedestrian and found that one percent from the overall street in a city remain in pedestrian cognitive [25]. Thus, these have shown a relation of street pattern and pedestrian movement in town can be determined by using axial-line.

This paper used axial-line as a parameter to determine street connectivity for pedestrian movement. Street connectivity in the axial-line graph is defined as the number of intersections $\left(I_{i j}\right)$ from the connection of a line in a street with the lines in other streets [7], [11], [23], [25], [26]. The intersection of streets is known as a node (Fig. 3).

$$
C_{\text {movement }}=\sum I_{i j}
$$

Thus, the connectivity for pedestrian movement $\left(C_{\text {movement }}\right)$ in the graph is analyzed according to Equation 3 using Axial-line Graph Analysis.

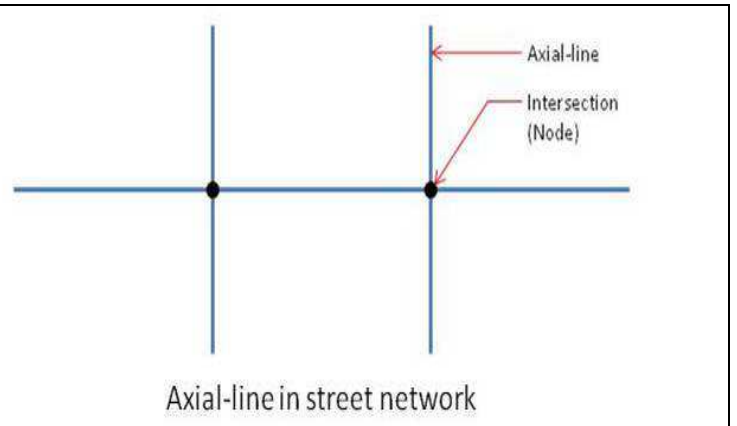

Fig. 3 Street connectivity for axial-line

\section{MATERIAL AND METHOD}

The small town is known as a community center where people use for industrial, business and social activity. It's performed essential functions of sales, retailing, trade, and craft, religious and administrative. This paper focused on a small town in Malaysia as a sample study. The sample is used to identify differences in street connectivity between the street network of old and new zones in Malaysian small town.

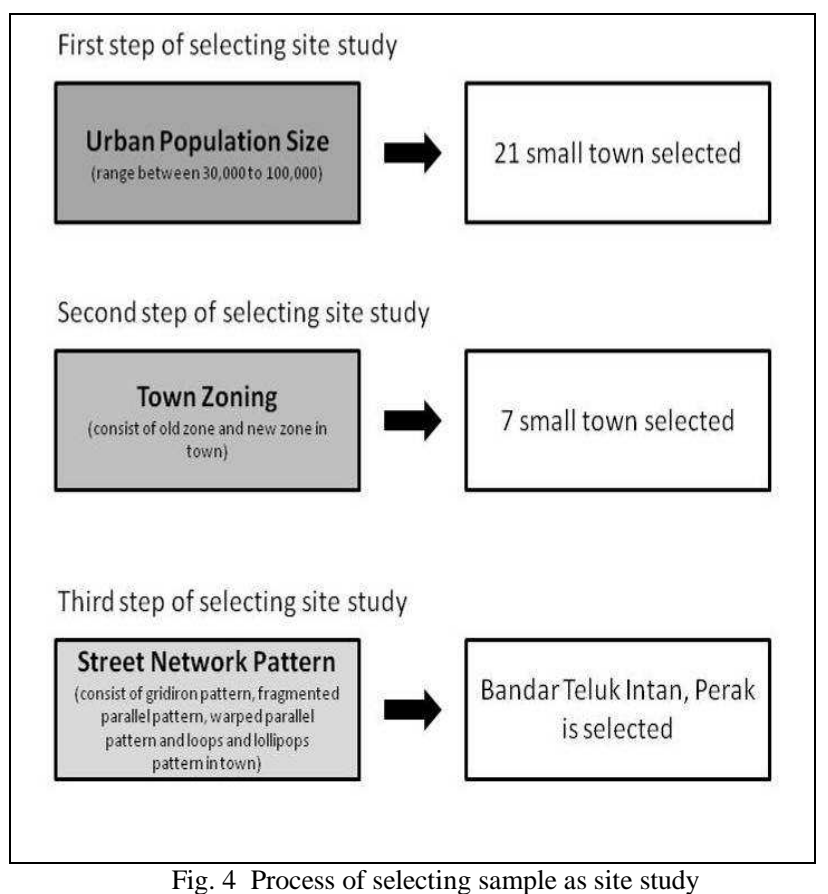

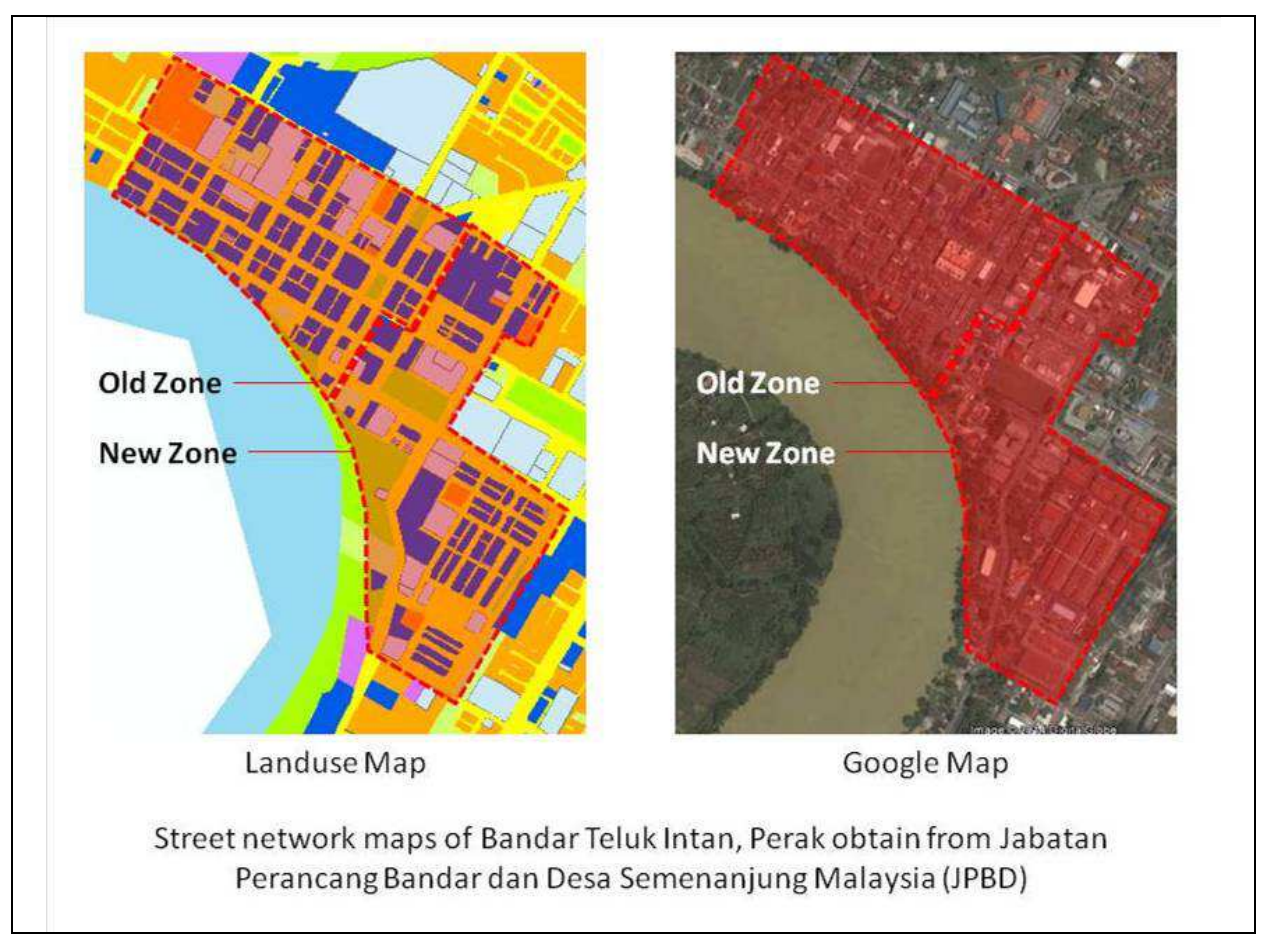

Fig. 5 Obtained data required for producing input data 


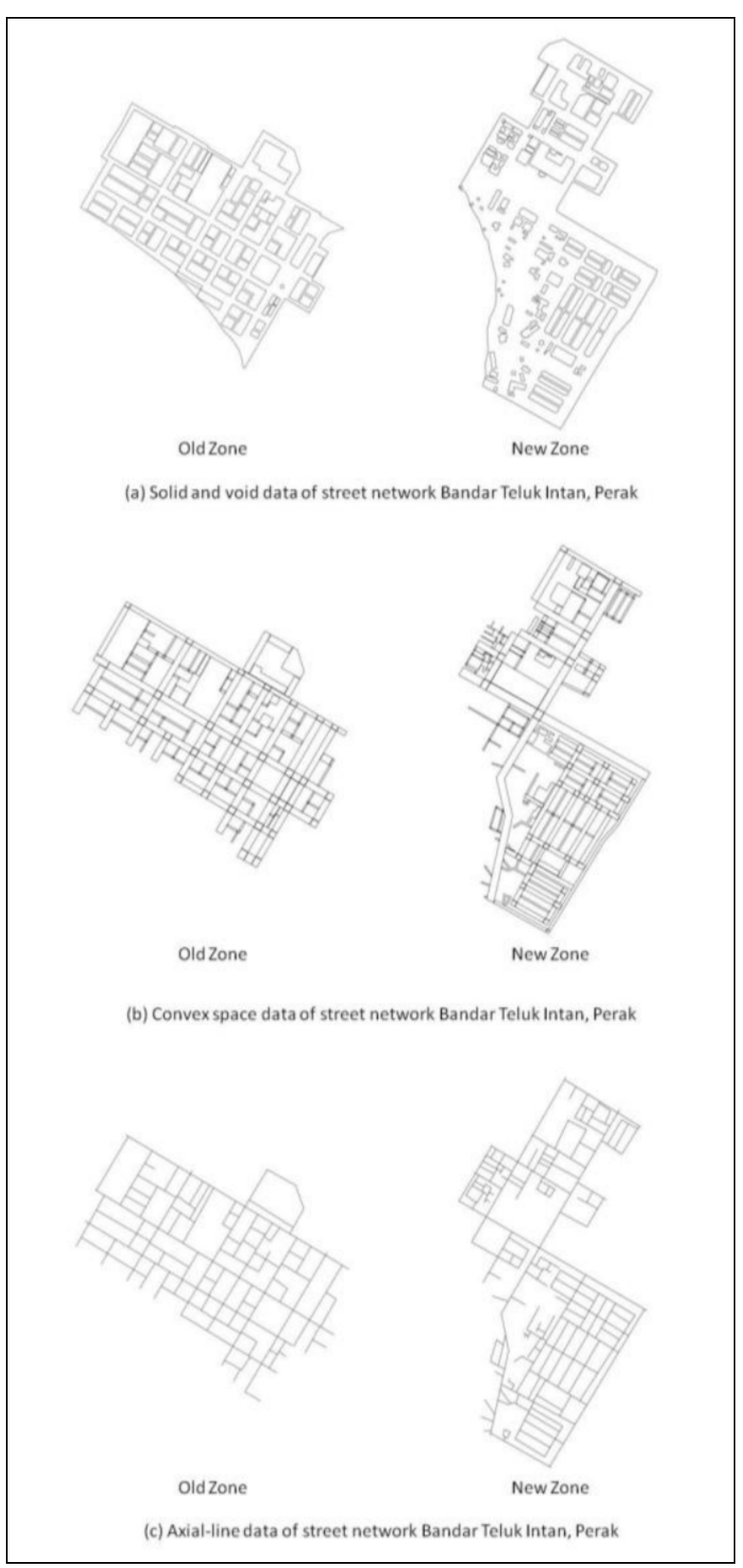

Fig. 6 Three sets of input data: (a) solid and void data, (b) convex space data, and (c) axial-line data

Small towns in Malaysia are facing a rapid development due to the influence of social-economic development. Thus, the selection of small town as the sample in this study required certain aspect related to the street network connectivity. The sample of a small town is selected to represent the small town in Malaysia, all small towns identified in Malaysia are filtered through three aspects; urban population size [27], town zoning [5], [28], and street network pattern [29].
Thus, Bandar Teluk Intan, Perak, Malaysia is selected based on the process of selecting the small town for the site study in Fig. 4.

Bandar Teluk Intan, Perak is addressed as a heritage town by the local authority because of the historical value from colonial period which still exists. The urban population size of the town is 41,701 . The town environment consists of the old zone which from the colonial period of the British and new zone which the area developed after Malaysian independence, built land uses of the low-rise residential area, low-density commercial area, and streets. The street network pattern of the town consists of gridiron, fragmented parallel, warped parallel, and loops and lollipops patterns. The street network and commercial development cover a total of 80 hectares of land.

In this study, the analyses require three sets of input data as shown in Fig. 6 based on parameters studied; (a) solid and void data, (b) convex space data, and (c) axial-line data. In producing the data, Google Map image and land use map of the street network pattern of Bandar Teluk Intan, Perak, Malaysia is obtained from Jabatan Perancang Bandar dan Desa Semenanjung Malaysia (JPBD) [30]. The maps of the street network pattern were digitized into drawing format (DXF) using AutoCAD 2012 as shown in Fig. 5. Then, the data were imported into Depthmap version 10 for data analyses.

\section{RESULTS AND DISCUSSION}

The results suggest that the differences of street connectivity for old and new zones in small town identified through pedestrian visualization, pedestrian interaction and pedestrian movement.

\section{A. Pedestrian Visualization for Old and New Zones}

The results from VGA showed that in the old zone (Fig. 7), space at junctions showed the higher connectivity by range color light green to red. This means that pedestrian will easily view junctions while they travel. However, the results for back-lane space indicated by dark blue color showed lower connectivity than the main road which indicates as green to light blue. Junctions are used to connect the view of a pedestrian in finding their destination even though space on the roads and back lanes is low visibility. Therefore, junctions in old zone used to be the pedestrian visual connector when traveling.

As can be seen in VGA results for a new zone in Fig. 7, only junction of the main road showed the highest connectivity, indicated by red color and main road showed a higher connectivity range from yellow to light blue. This means that main road is used to be the most viewed space by pedestrian and centralize by its junction. However, results for roads in blocks showed the lower connectivity range from light blue to dark blue. This means the street system for new zone used main roads in bringing pedestrian to roads in blocks, by using street features such as signage or landmark as navigational information to pedestrians. Therefore, main roads in new zone play an important role in making pedestrian view the town. 


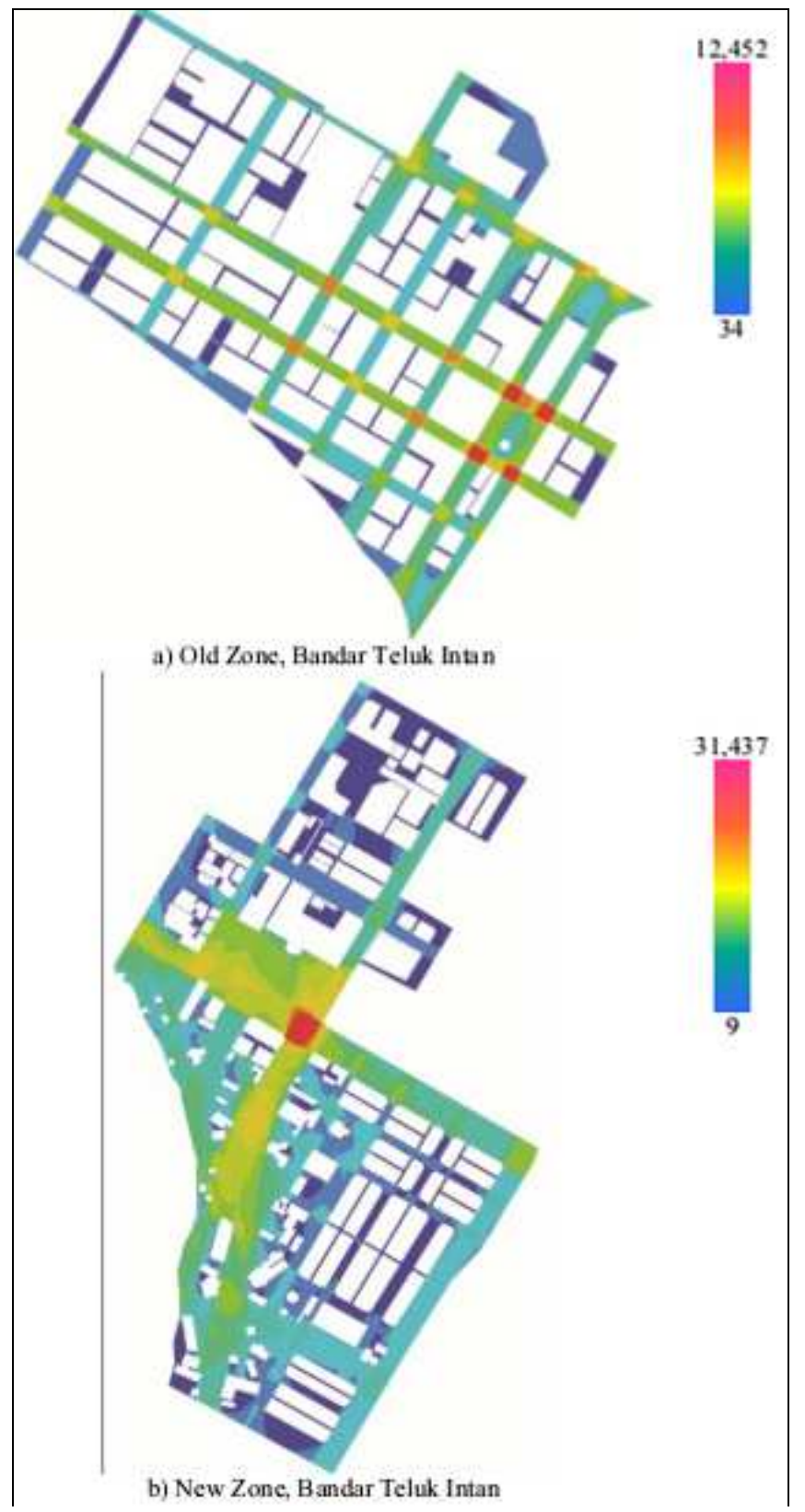

Fig. 7 Street connectivity for pedestrian visualization

The differences of street connectivity for pedestrian visualization in the old zone and new zone are visibility space at junctions and main roads. This is because the street pattern in the old zone is designed in a period where walking is the main travelling mode while the design of street network pattern in the new zone is focused on transportation which the main traveling mode used by people nowadays. These are consistent with the study by [2] suggested that street network pattern by gridiron pattern important for encouraging non-automobile modes of travel. However, in the context of the small town which consists of the old zone and new zone with various street patterns, due to the differences existed, the used of street features for navigation information are needed in making both old zone and new zone well connected.

\section{B. Pedestrian Interaction for Old and New Zones}

Convex space is analyzed by CSGA showed in Fig. 8.

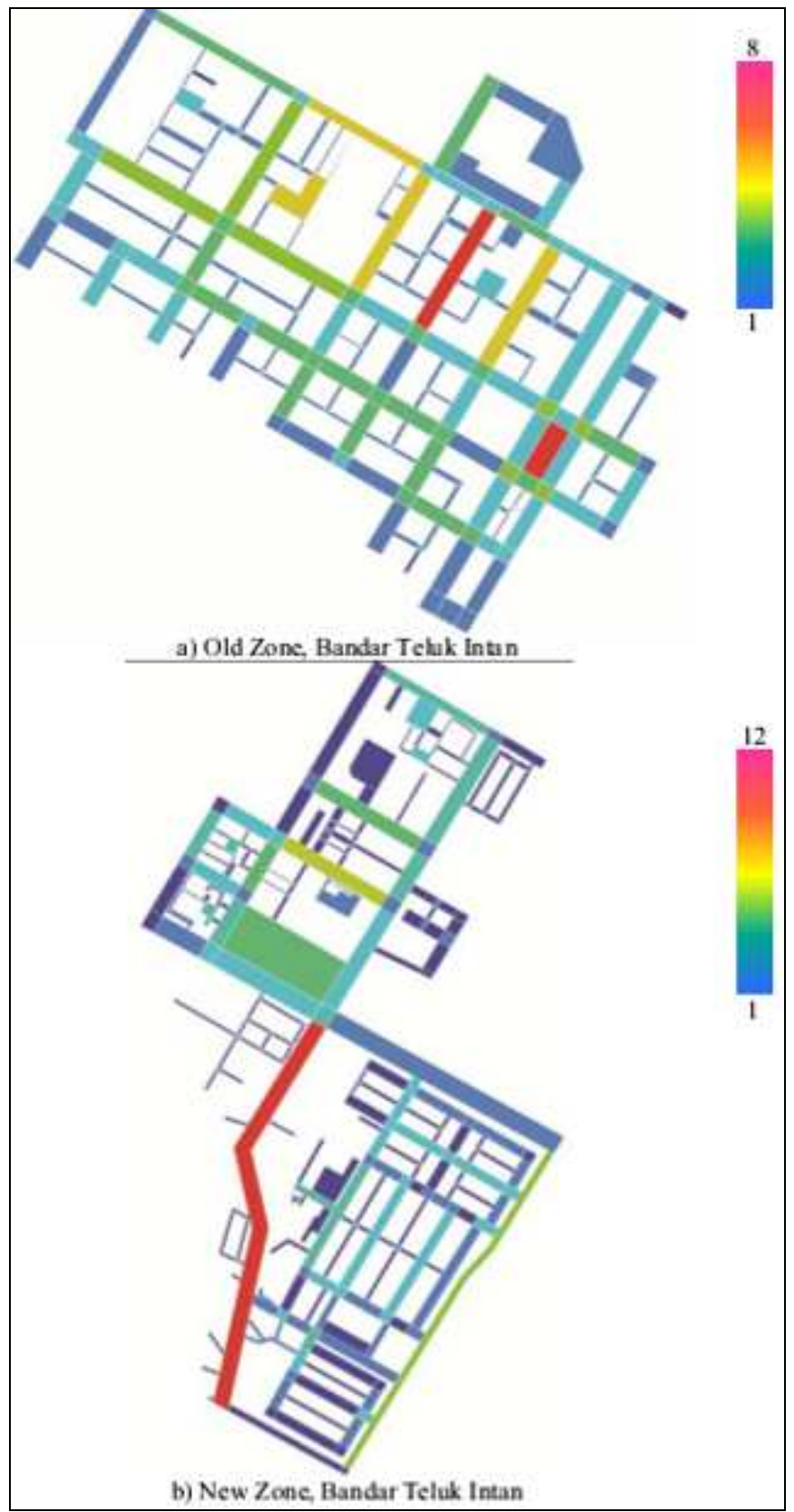

Fig. 8 Street connectivity for pedestrian interaction

The result from the CSGA for old zone indicated that the highest connectivity spotted at two spaces which are near the market and square. This means that both spaces are a meeting point for the pedestrian. These spaces are designed by connecting with other street spaces to bring pedestrian to interact with other spaces into a space. However, the result of CSGA for the new zone (Fig. 8) showed that the highest connectivity is spotted at main road space indicated by red color. This means that there are a lot of ins and outs of blocks connect with main roads. Thus, there will be an interaction by a pedestrian while they move in the main road.

The differences of street connectivity for pedestrian interaction in the old zone and new zone are the interaction spaces, street at the market and square and main roads. This is because of the spaces connecting with the interaction space in old zone use to support the land use activities while 
the interaction space at new zone used to bring pedestrian to the destinations. These findings are parallel to the study by [31] that interaction space created from the pedestrian walk to a central focal point such as a school in a neighborhood environment. However, in the context of a small town, the result showed the difference in the type of space where the interaction space in small town fit the social activities in the urban environment.

\section{Pedestrian Movement for Old and New Zones}

Fig. 9 shows the analysis of axial line by AGA.

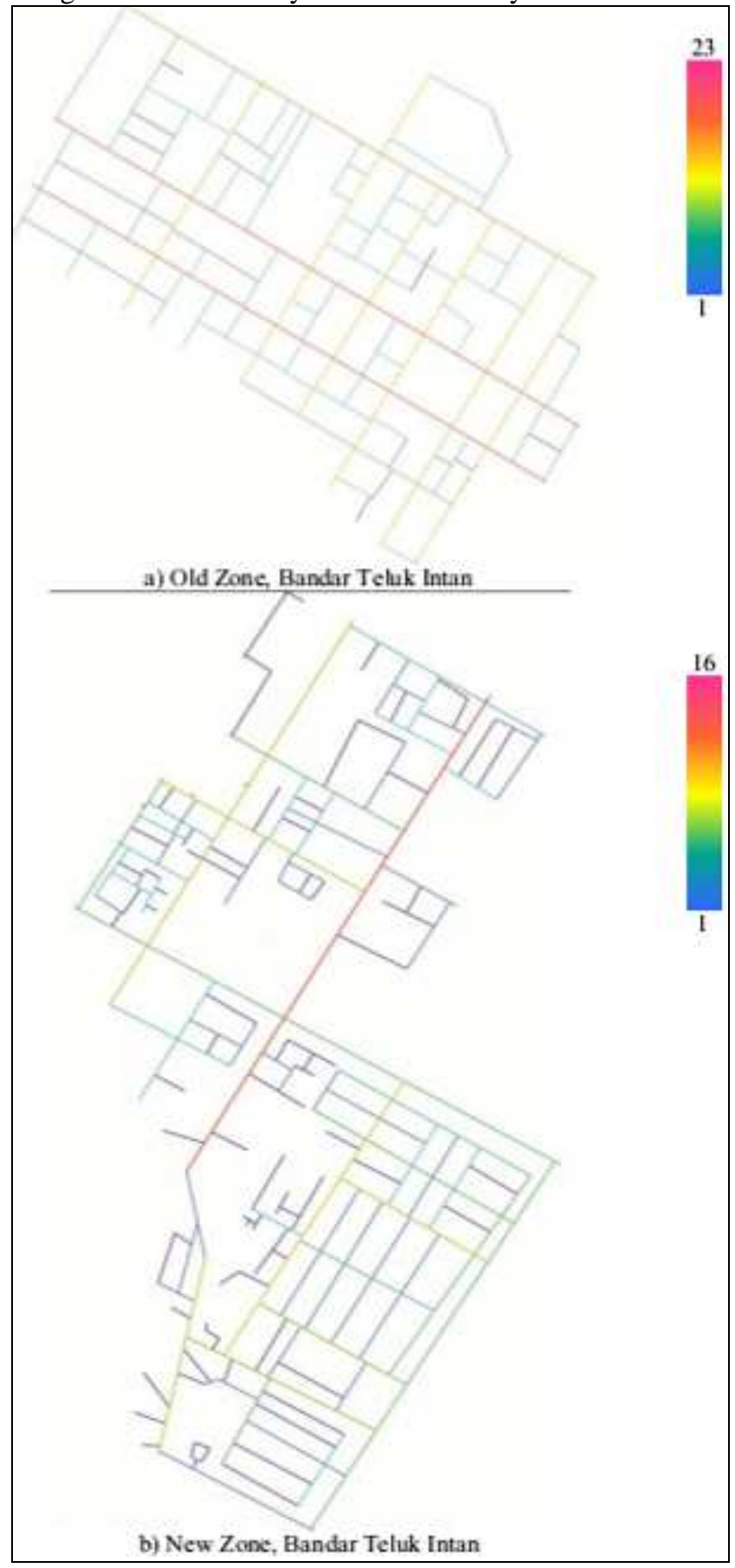

Fig. 9 Street connectivity for pedestrian movement

From the analysis on axial-line, the results of the AGA for old zone showed that high connectivity for main roads ranges from red to light green and low connectivity for back- lanes range from green to dark blue (Fig. 9). These suggest that the streets are connected all over the town.

As a result, these decrease the possibility for pedestrians to get lost in the back-lanes because they will always meet the main road when they travel. However, AGA results for new zone showed that highest connectivity showed at main roads indicate by red color and low connectivity at roads in blocks range from yellow to dark blue. These mean that street network at new zone is centralized by main roads to move into the blocks. Therefore, there are two levels of pedestrian movement in street network of the new zone of the small town; the first level for a pedestrian to find a destination block in the main roads and the second level for a pedestrian to find destinations in blocks.

The differences of street connectivity for pedestrian movement in the old zone and new zone are on the functions of main roads. Main roads in the old zone are becoming a guide in defining a route to a destination while in the new zone, main roads used by a pedestrian to find blocks. This finding fits a study by [25] that main road name used as a reference in wayfinding process. This means that the pedestrian would find the main road for them to find destinations. However, in small town context consist of the old zone and a new zone, the main roads are used as a guide but in different functions based on its environments.

Hence, overall results suggest that the differences of street connectivity in the old zone and a new zone of small town lead urban designer to consider in the development of urban environment especially small town for creating a better social development of the town.

\section{CONCLUSIONS}

This paper implies that streets in small towns are connecting pedestrian with their destination differently according to street network patterns of the town. The differences of pedestrian visualization, pedestrian interaction and pedestrian movement in small town influence pedestrian perceive the town. Therefore, urban designer such as planner, architect, and landscape architect needs to understand the street connectivity in street network patterns to meet the needs of pedestrian behavior in small town. However, the results of the analyses in this study need to be triangulated with other results from the interviews or pedestrian route mapping, to make sure the findings more valid and reliable. Therefore, studies on pedestrian spatial knowledge, and route mapping in small towns are recommended for further discussions on the study.

\section{ACKNOWLEDGMENT}

We would like to thank Jabatan Perancang Bandar dan Desa Semenanjung Malaysia (JPBD) for providing data required in this study.

We also acknowledge researchers from Greenovation Research Group, Faculty of Built Environment, Universiti Teknologi Malaysia for their constructive comments and advice, as well as their time and expertise.

\section{REFERENCES}

[1] M. Tomko, S. Winter, and C. Claramunt. Experiential hierarchies of streets, Computers, Environment and Urban Systems, 32(1) (2008) 41-52. 
[2] W.E. Marshall and N.W. Garrick. The effect of street network design on walking and biking, Journal of the Transportation Research Board, (2010) 103-115.

[3] E. Leslie, et al. Walkability of local communities: using geographic information systems to objectively assess relevant environmental attributes, Health Place, 13(1) (2007) 111-22.

[4] B.B. Cutts, et al. City structure, obesity, and environmental justice: an integrated analysis of physical and social barriers to walkable streets and park access, Soc Sci Med, 69(9) (2009) 1314-22.

[5] N.Z. Harun and R.A.J. Jalil. The morphological history of the Malaysian urban form, International Proceedings of Economics Development and Research, 48(24) (2012) 111-116.

[6] R. Ramele, Z. Isnin, and I.L. Jabar. Urban morphology of buffer zone and its survival in the historical city of Malacca, Journal of Built Environmental, 7(1) (2010) 35-41.

[7] J. Peponis, et al. On the generation of linear representations of spatial configuration, Proceeding of Space Syntax First International Symposium, 3 (1997)

[8] B. Jiang, C. Claramunt, and B. Klarqvist. Integration of space syntax into GIS for modelling urban spaces, Journal of Applied Earth Observation and Geoinformation, 2(3) (2000) 161-171.

[9] W.S.N. Wan Mohamad and I. Said. A review of variables of urban street connectivity for spatial connection, IOP Conference Series: Earth and Environmental Science, 18 (2014).

[10] O. Adegoke, A. Ab Aziz, and Y. Yusof. Formal analysis of an agent support model for behaviour change intervention, International Journal on Advanced Science, Engineering and Information Technology, 6(6) (2016) 1074-1080.

[11] F. van der Hoeven and A. van Nes. Improving the design of urban underground space in metro stations using the space syntax methodology, Tunnelling and Underground Space Technology, 40((2014) 64-74.

[12] S.K. Jeong and Y.U. Ban. Computational algorithms to evaluate design solutions using Space Syntax, Computer-Aided Design, 43(6) (2011) 664-676.

[13] D.E. Önder and Y. Gigi. Reading urban spaces by the space-syntax method: A proposal for the South Haliç Region, Cities, 27(4) (2010) 260-271.

[14] W.H.K. Lam, et al. Wayfinding in the passenger terminal of Hong Kong International Airport, Journal of Air Transport Management, 9((2003) 73-81.

[15] A. Churchill, et al. Quantifying and validating measures of airport terminal wayfinding, Journal of Air Transport Management, 14(3) (2008) 151-158

[16] M.L. Tam. An optimization model for wayfinding problems in terminal building, Journal of Air Transport Management, 17(2) (2011) 74-79.
[17] I. Omer and R. Goldblatt. The implications of inter-visibility between landmarks on wayfinding performance: An investigation using a virtual urban environment, Computers, Environment and Urban Systems, 31(5) (2007) 520-534

[18] P.C. Dawson. Space syntax analysis of Central Inuit snow houses, Journal of Anthropological Archaeology, 21 (2002) 464-480.

[19] S.-K. Jeong and Y.-U. Ban. Developing a topological information extraction model for space syntax analysis, Building and Environment, 46(12) (2011) 2442-2453.

[20] H.-K. Kim and D.W. Sohn. An analysis of the relationship between land use density of office buildings and urban street configuration, Journal of Cities, 19(6) (2002) 409-418.

[21] J. Peponis, S. Bafna, and Z. Zhang. The connectivity of streets: reach and directional distance, Journal of Environment and Planning B, 35 (2008) 881-901.

[22] B. Hillier and J. Hanson. The socio logic space. 1984, United Kingdom: Cambridge University Press.

[23] M. Batty, A new theory of space syntax. 2004, Centre for Advanced Spatial Analysis: University College London, London.

[24] S. Porta, P. Crucitti, and V. Latora. The network analysis of urban streets: a primal approach, Journal of Environment and Planning B, 33 (2006) 705-725.

[25] B. Jiang. A topological pattern of urban street networks: Universality and peculiarity, Physica A: Statistical Mechanics and its Applications, 384(2) (2007) 647-655.

[26] B. Jiang, C. Claramunt, and M. Batty. Geometric accessibility and geographic information: extending desktop GIS to space syntax, Journal of Computers, Environment and Urban Systems, 23 (1999) 127-146.

[27] A.K. Sołtys. Small towns in Poland - barriers and factors of growth, Procedia - Social and Behavioral Sciences, 19 (2011) 363-370.

[28] N.Z. Harun, M. Mansor, and I. Said. The Experience of Diversity in Open Spaces of Two Historical Towns in Malaysia, Procedia - Social and Behavioral Sciences, 85 (2013) 582-591.

[29] S.M. Rifaat, R. Tay, and A. de Barros. Effect of street pattern on the severity of crashes involving vulnerable road users, Accid Anal Prev, 43(1) (2011) 276-83.

[30] E. Anas and Y. Yuzirwan. Evaluation of land use change in the district Dhamasraya, International Journal on Advanced Science, Engineering and Information Technology, 6(1) (2016) 97-103.

[31] M.Z. Maleki, M.F.M. Zain, and A. Ismail. Variables communalities and dependence to factors of street system, density, and mixed land use in sustainable site design, Sustainable Cities and Society, 3 (2012) 46-53. 